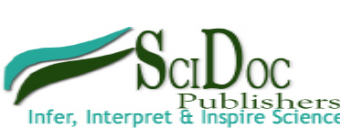

International Journal of Bioorganic Chemistry \& Molecular Biology (IJBCMB)

ISSN 2332-2756

\title{
Future Frontiers in Organic Synthesis
}

Editorial

Leow $\mathrm{D}^{1 *}$, Thorat $\mathrm{V} \mathrm{H}^{1}$, Santra $\mathrm{S}^{1}$, Su $\mathrm{Y}^{1}$

Department of Chemistry, National Tsing Hua University, Hsinchu 30013, Taiwan, R.O.C.

\section{*Corresponding Author:}

Dasheng Leow*

Department of Chemistry, National Tsing Hua University,

Hsinchu, 30013, Taiwan, R.O.C.

Tel: +886 35731091, Fax: +886 35711082

dsleow@mx.nthu.edu.tw

Received: December 14,2013

Published: January 28, 2014

Citation: Leow D, Thorat V H, Santra S, Su Y(2014) Future Frontiers in Organic Synthesis. Int J Bioorg Chem Mol Biol. 2(1e), 1-2. doi: http:// dx.doi.org/10.19070/2332-2756-140004e

Copyright: Leow $\mathrm{D}^{\mathscr{O}}$ 2014. This is an open-access article distributed under the terms of the Creative Commons Attribution License, which permits unrestricted use, distribution and reproduction in any medium, provided the original author and source are credited.

The role of organic synthesis to the mankind is of paramount importance since the early nineteen century [1]. In 1828, Friedrich Wöhler discovered the synthesis of urea from ammonium cyanate, marking the starting point of modern organic synthesis. Wöhler concluded to his mentor Jöns Jacob Berzelius, "I cannot, so to say, hold my chemical water and must tell you that I can make urea without thereby needing to have kidneys, or anyhow, an animal, be it human or dog". Since then, organic synthesis has become an indispensable tool in industries such as petrochemicals, pharmaceutical, flavors, fragrances, agrochemical, and others. This is evident by the number of Nobel prizes awarded to organic chemists. The Nobel Prize in Chemistry 2001 was awarded to William S. Knowles, Ryoji Noyori, and K. Barry Sharpless for their work in asymmetric synthesis. This was followed by the award of the Nobel Prize in Chemistry 2005 to Yves Chauvin, Robert H. Grubbs and Richard R. Schrock "for the development of the metathesis method in organic synthesis". And just recently, Richard F. Heck, Ei-ichi Negishi and Akira Suzuki won the Nobel Prize in Chemistry 2010 for "palladium-catalyzed cross couplings in organic synthesis".

As we progress into the 21 st century, the field of organic synthesis experiences exponential growth [2]. This phenomenon is fuelled by two exceptional fields in the last 15 years, which are namely asymmetric organocatalysis [3] and transition metal catalyzed $\mathrm{C}-\mathrm{H}$ bond activation [4-5]. The concept of asymmetric organocatalysis is not entirely new. It can be dated back to the 1950s when Pracejus reported the enantioselective ester synthesis from ketenes using natural cinchona alkaloids [6]. Over the next few decades, this area was heavily overlooked. However in 2000, two seminal reports by List, Barbas et al.[7] and Macmillan et al. [8] sparked off the "gold rush" in the last decade. On the other hand, insertion of transition metals into carbon-hydrogen bond has been well-documented [9]. Such methods can expedite the synthesis of architecturally complex molecules. Spurred by high demands from the pharmaceutical, agrochemical, and other relevant industries, the synthetic application value of $\mathrm{C}-\mathrm{H}$ bond activation is finally realized in recent years.

As we continue to witness the high intensity research activities in these two areas, what can we expect in the future? The general trend is towards the theme of green chemistry. Among the several promising ones are: (a) fluorine chemistry; (b) radical chemistry; (c) fixation of carbon dioxide. Among the pharmaceuticals, $20 \%$ of them contain fluorine atom. Fluorinated compounds are found to increase the probability of hitting a drug compound significantly. Moreover, fluorine chemistry is not as well studied as compared to other subfields.

Therefore fluorine chemistry is expected to expand rapidly over the next ten years.

Another upcoming hot topic will be the radical chemistry. Since early 20th century, radicals are already discovered. They are extremely powerful species but they come with associated problems too. Firstly, they are difficult to generate in a mild way. Secondly, these reactive radicals are hard to control in terms of selectivity. In recent years, several groups have made advances in this area [10-11] and many more are on the way. The wild radical species will be tamed in time to come. Last but not least, the pressing issue of greenhouse gases is of global concern. If more carbon dioxide can be utilized for organic synthesis, it will reduce the carbon footprint of humans on earth [12]. The only problem with carbon dioxide is its intrinsic high stability. The current challenge is to reduce the exorbitant level of energy that is require to activate carbon dioxide for organic synthesis.

In conclusions, the three potential areas in organic synthesis of wide interest and importance have been highlighted. Through these technology innovations, they will have great beneficial impact on mankind. Organic chemists are one of the most creative people and new areas will also start to emerge down the road. We can never predict exactly what kind of new developments will take place in future. However we can be sure that the future of organic synthesis will remain as bright as it is of current and past.

\section{References}

[1]. Nicolaou KC, Montagnon T (2008) Molecules that changed the world. WILEY-VCH Verlag GmbH \& Co. KGaA, Weinheim, Germany.

[2]. Ding K, Dai LX, Eds. (2012) Organic chemistry: breakthroughs and perspectives. WILEY-VCH Verlag GmbH \& Co. KGaA, Weinheim, Germany.

[3]. Dalko PI, Ed. (2013) Comprehensive enantioselective organocatalysis: catalysts, reactions, and applications. WILEY-VCH Verlag GmbH \& Co. KGaA, Weinheim, Germany. 
[4]. Chen X, Engle KM, Wang DH, Yu JQ (2009) Palladium(II)-catalyzed C-H activation/C-C cross-coupling reactions: versatility and practicality. Angew. Chem. Int. Ed. 48:5094-5115.

[5]. Lyons TW, Sanford MS (2010) Palladium-catalyzed ligand-directed C-H functionalization reactions. Chem. Rev. 110:1147-1169.

[6]. Pracejus H (1960) Organische katalysatoren, LXI. asymmetrische synthesen mit ketenen, I. alkaloid-katalysierte asymmetrische synthesen von -phenylpropionsäureestern. Justus Liebigs Ann. Chem. 634:9-22.

[7]. List B, Lerner RA, Barbas CF III (2000) Proline-catalyzed direct asymmetric aldol reactions. J. Am. Chem. Soc. 122:2395-2396.

[8]. Ahrendt KA, Borths CJ, MacMillan DWC (2000) New strategies for organic synthesis: the first highly enantioselective organocatalytic Diels-Alder reac- tion. J. Am. Chem. Soc. 122:4243-4244.

[9]. Shilov AE, Shul'pin GB (1997) Activation of C-H bonds by metal complexes. Chem. Rev. 97:2879-2932.

[10]. Nicewicz D, Macmillan DWC (2008) Merging photoredox catalysis with organocatalysis: the direct asymmetric alkylation of aldehydes. Science 322:77-80.

[11]. Fujiwara Y, Dixon JA, O'Hara F, Daa Funder E, Dixon DD, Rodriguez RA, Baxter RD, Herlé B, Sach N, Collins MR, Ishihara Y, Baran PS (2012) Practical and innate carbon-hydrogen functionalization of heterocycles. Nature 492:95-100.

[12]. Sakakura T, Choi JC, Yasuda H (2007) Transformation of carbon dioxide. Chem. Rev.107:2365-2387. 